\title{
Predisposing factors, neurological complications and sequels of guillain barre syndrome at discharge: experience in an ICU of a third level hospital
}

\author{
E Portugal Rodríguez, A Berrazueta Sánchez de Vega, R Vara Arlanzón, E Martínez Barrio, M Del Valle Ortiz, \\ JA Fernández Ratero, ME Perea Rodríguez, M Gero Escapa, M Montero Baladía, S Calvo Simal
}

From ESICM LIVES 2015

Berlin, Germany. 3-7 October 2015

\section{Introduction}

Guillain Barre Syndrome (GBS) is an autoimmune inflammatory polyneuropathy characterized by flaccid areflexic paralysis, albuminocytologic dissociation in the CSF and demyelination. Clinical weakness is marked by axonal injury not by the demyelination; therefore axonal form has a worse prognosis.

\section{Objectives}

To describe the characteristics of patients admitted with GBS. Analyze its' triggers and severity (APACHE II). To examine subtypes and determine whether patients with axonal form (AF) presented more complications, mortality, sequels and length of stay (LOS) than the patients with demyelinating form (DF). To correlate days of invasive mechanical ventilation (IMV) with complications and sequels at discharge.

\section{Methods}

Descriptive, observational study of all patients with GBS admitted to a general ICU during 13 years. Chi-square and exact Fisher test were used. Variables: sex, age, gravity, stay, subtypes, triggers, complications, and neurological sequels (NS): mild (minor symptoms, enable to run), moderate (able to walk 10 meters unaided), severe (able to walk more than 10 meters with assistance) and very severe (sofa-bed life or need of IMV).

\footnotetext{
Burgos University Hospital, Burgos, Spain
}

\section{Results}

We analyzed 15 cases of GBS (66.6\% males). Mean age 61 ( \pm 19.8). Median APACHEII $11.75 \pm$ 7.1. Mean ICU LOS $63.60 \pm 100.2$ days and hospital LOS $90.67 \pm 116.5$. In the electromyographic recording, $50 \%$ had DF and $50 \%$ had the AF. The $33 \%$ had a respiratory trigger, gastrointestinal in $20 \%, 7 \%$ after vaccination and $20 \%$ fever of unknown origin. Serologic test were positive in 5 patients. C. jejuni (2), VEB (1), H. pylori (1) and both B.Burdogferi plus C. jenuni (1). Just 13 cases needed IMV with mean duration $39.92 \pm 31,52$ days. There was extubation failure in $46 \%$ of the cases; $80 \%$ required tracheostomy. We diagnosed nosocomial infections in $87 \%$, of which $33 \%$ was associated with IMV (ventilator associated pneumonia, VAP). The ICU mortality was $20 \%$. No significant relationship (SR) was found between the AF and the presence of more complications, mortality, ICU or hospital LOS. Regarding the NS observed, $16.6 \%$ were mild; $25 \%$ severe, $41.6 \%$ very severe and there was no SR between the worst prognosis and the AF. We found SR between IMV and VAP, with a greater duration of IMV in the group in which VAP is present $(p=0.041)$. Statistical association exits between longer duration of IMV and severity of sequels at discharge $(\mathrm{p}=0.015)$.

\section{Conclusions}

GBS is a rare disease with low mortality and prolonged hospital and ICU LOS. No SR is evidenced between AF and greater complications, hospital stay, mortality and sequels at discharge. The duration of IMV predicted higher rates of VAP. The severity of sequels at discharge was associated with more days of IMV. 


\section{Reference}

1. Guillain Barré Syndrome, NEJM Jun 2012. Guillain Barré syndrome and variants, Neurol Clinic May 2013; Axonal Guillain-Barré syndrome: concepts and controversies. The Lancet Neurol. Dec.2013..

doi:10.1186/2197-425X-3-S1-A993

Cite this article as: Portugal Rodríguez et al:: Predisposing factors,

neurological complications and sequels of guillain barre syndrome at discharge: experience in an ICU of a third level hospital. Intensive Care Medicine Experimental 2015 3(Suppl 1):A993.

\section{Submit your manuscript to a SpringerOpen ${ }^{\circ}$ journal and benefit from:}

- Convenient online submission

- Rigorous peer review

- Immediate publication on acceptance

- Open access: articles freely available online

- High visibility within the field

- Retaining the copyright to your article

Submit your next manuscript at $\gg$ springeropen.com 